\title{
Navigating the crowd: visualizing coordination between genome dynamics, structure, and transcription
}

\author{
Haitham A. Shaban ${ }^{1,2^{*}}$ D, Roman Barth ${ }^{3}$ and Kerstin Bystricky $y^{4,5^{*}}$
}

\author{
* Correspondence: h_shaban@ \\ aucegpt.edu; kerstin.bystricky@univ- \\ tlse3.fr \\ 'Spectroscopy Department, Physics \\ Division, National Research Centre, \\ Dokki, Cairo 12622, Egypt \\ ${ }^{4}$ Laboratoire de Biologie Moléculaire \\ Eucaryote (LBME), Centre de \\ Biologie Intégrative (CBI), CNRS, \\ UPS, University of Toulouse, 31062 \\ Toulouse, France \\ Full list of author information is \\ available at the end of the article
}

\begin{abstract}
The eukaryotic genome is hierarchically structured yet highly dynamic. Regulating transcription in this environment demands a high level of coordination to permit many proteins to interact with chromatin fiber at appropriate sites in a timely manner. We describe how recent advances in quantitative imaging techniques overcome caveats of sequencing-based methods ( $\mathrm{Hi}-\mathrm{C}$ and related) by enabling direct visualization of transcription factors and chromatin at high resolution, from single genes to the whole nucleus. We discuss the contribution of fluorescence imaging to deciphering the principles underlying this coordination within the crowded nuclear space in living cells and discuss challenges ahead.
\end{abstract}

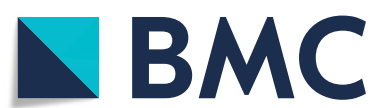

(c) The Author(s). 2020 Open Access This article is licensed under a Creative Commons Attribution 4.0 International License, which permits use, sharing, adaptation, distribution and reproduction in any medium or format, as long as you give appropriate credit to the original author(s) and the source, provide a link to the Creative Commons licence, and indicate if changes were made. The images or other third party material in this article are included in the article's Creative Commons licence, unless indicated otherwise in a credit line to the material. If material is not included in the article's Creative Commons licence and your intended use is not permitted by statutory regulation or exceeds the permitted use, you will need to obtain permission directly from the copyright holder. To view a copy of this licence, visit http://creativecommons.org/licenses/by/4.0/. The Creative Commons Public Domain Dedication waiver (http://creativecommons.org/publicdomain/zero/1.0/) applies to the data made available in this article, unless otherwise stated in a credit line to the data. 
microscopy-based single-cell time course experiments a necessity to understand the dynamic behavior of chromatin. For a comprehensive comparison between different imaging techniques used to studying genome organization and transcription, we refer the reader to recent reviews [8-11]. In addition, imaging techniques can be multiplexed for simultaneous visualization of a multitude of chromatin constituents and are amenable to highthroughput analysis of genome organization at kilobase resolution [10]. While super resolution imaging-based approaches are often performed in fixed cells, time-resolved wholechromatin imaging recently revealed that chromatin moves in a spatially and temporally correlated manner at a nanoscale resolution [12, 13]. Such correlated motion might be caused by active mechanisms [14], including transcription [15, 16] and/or polymer properties [17]. In silico, physical modeling of data from chromosome conformation capture techniques and fluorescence imaging produced several models which describe genome organization in the context of biological processes such as transcription $[18,19]$. Comprehensive time-resolved data complemented with static and ensemble data now bear great promise to correlate changes in the 3D organization to transcription.

Here, we describe how recent advances in live-cell imaging of chromatin in eukaryotic cells enriched our understanding of genome organization at different spatial and temporal scales. We start by considering the complementary views that wellestablished and yet continuously developing sequencing-based "C"-methods (henceforth $\mathrm{Hi}-\mathrm{C}$ ) and imaging-based methods can offer. We then outline various strategies to interrogate chromatin structure and/or dynamics in three-dimensional space and time, from a single gene to the complete genome, and describe how transcription activity influences chromatin folding and dynamics. We finally discuss how physical principles can explain the spatio-temporal coordination between the chromatin structure and dynamics and transcription in the nucleus.

\section{Fluorescence imaging and Hi-C: complementary and controversial views}

Hi-C revolutionized our knowledge of genome structure: a hierarchy of structural elements was discovered, the most prominent ones being DNA loops, topologically associated domains (TADs), and compartments [20-22]. While those elements are derived from a population average of structures, single-cell Hi-C has confirmed what cell biologists have known for decades that chromosome and chromosome domain conformations vary from cell to cell [23-27]. Distance measurements between FISH-labeled loci can validate selected features seen in models established from Hi-C maps [28-30], but distances do not necessarily correlate with contact frequencies [27, 31, 32], a tendency confirmed by high-throughput approaches [33, 34]. Furthermore, it is tedious to probe distances throughout the whole genome since FISH probes must be designed for each region of interest and can thus detect only a subset of chosen genomic loci in a reasonable time.

Hi-C and derived methods can assess the probability of crosslinking which is a measure of the frequency that chromatin loci are in proximity, probing spatial distances in the range of $\sim 400-600 \mathrm{~nm}$ [35]. By imaging, it is possible to quantify the distribution of actual spatial distances between any two or more loci (Fig. 1), making "C" and imaging complementary approaches [37]. Imaging also allows to characterize the shape of a given genomic region of interest [38] and to monitor the positioning of genes relative to nuclear compartments which can be visualized simultaneously [33, 39, 40] (Fig. 1). 


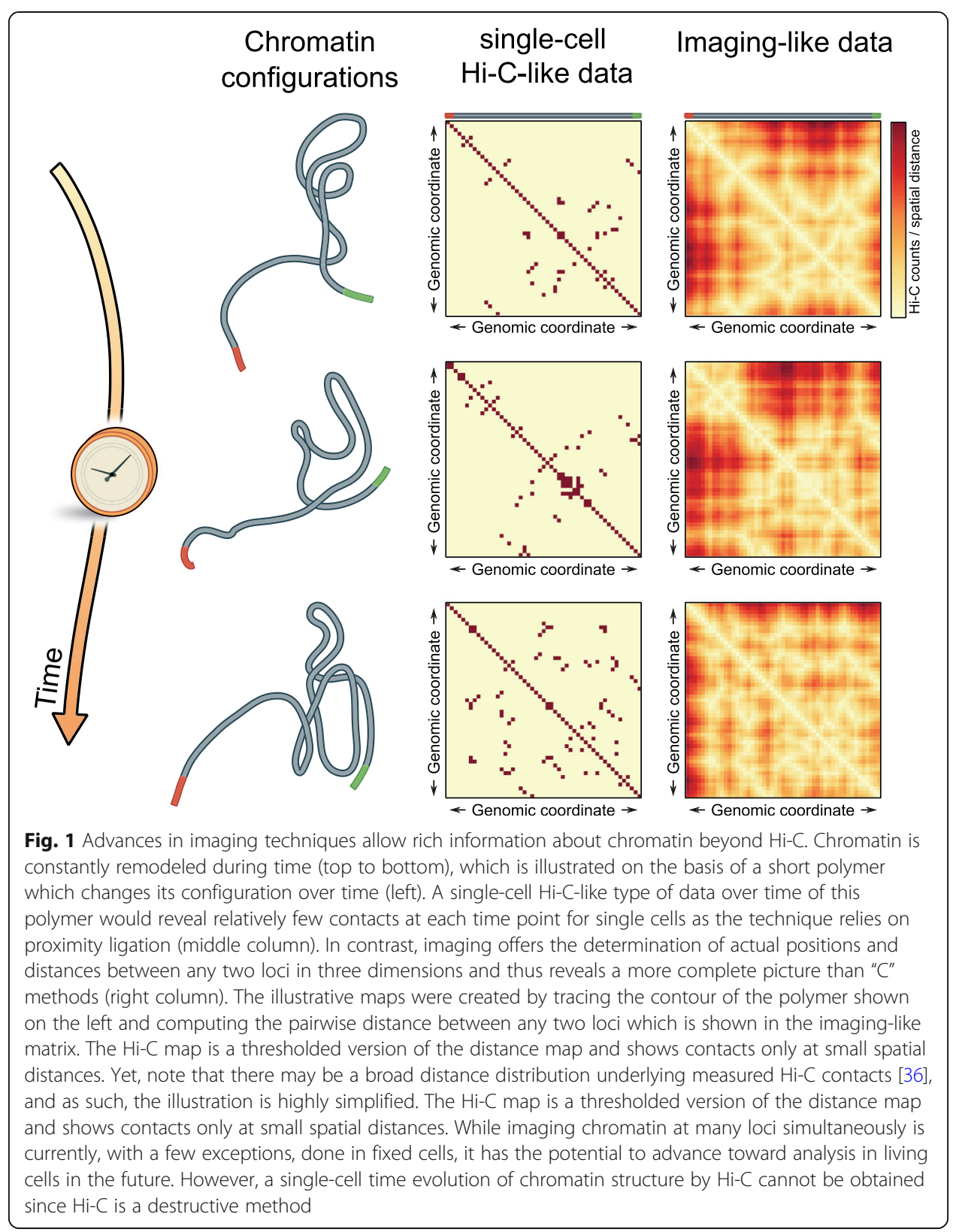

With the advent of sequential FISH [31], the three-dimensional folding of chromatin regions was probed directly in single cells and in situ (Fig. 2). Cooperative three-way interactions between loci [41] not seen previously using population-averaged contact maps were identified. Imaging further showed that TADs appear as discrete nanocompartments, which are spatially arranged side by side [41-43], although contact frequencies between loci within TADs only slightly ( 2 -fold) increased compared to loci within neighboring TADs [27, 44]. Integrating multiplexed imaging of RNA [45, 46] with sequential DNA FISH $[42,43]$ revealed that genes located at TAD boundaries were transcribed more frequently than genes within the TAD's interior highlighting that features of local chromatin structure and transcription activity are related.

Despite their success, three-dimensional chromatin structures derived from either sequential DNA FISH imaging or reconstructed from Hi-C maps are currently limited to 


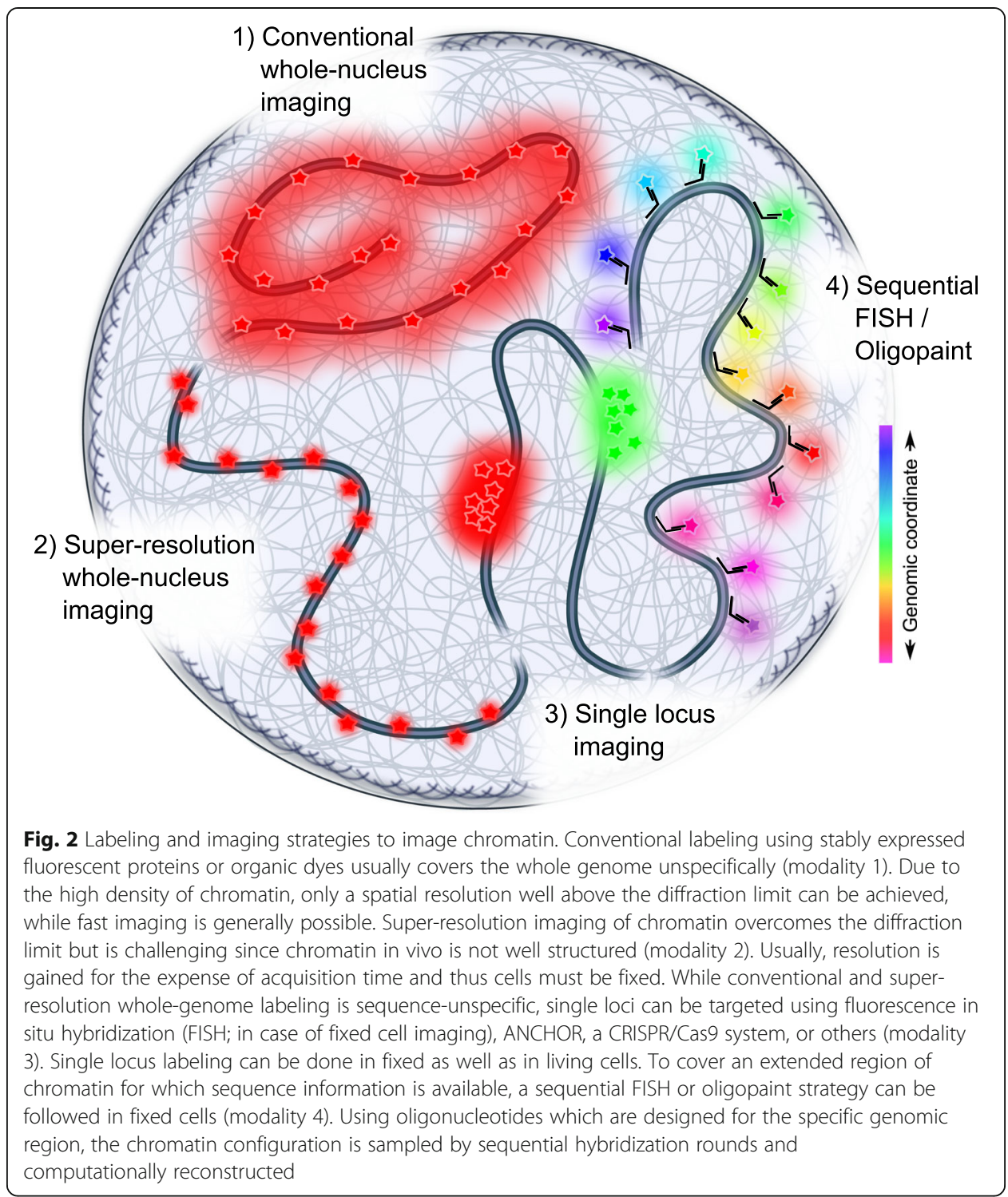

(i) fixed cells and (ii) a genomic resolution of $\sim 2 \mathrm{~kb}$ [43], although sequencing-based techniques to map contacts at the nucleosome level are being developed [47, 48]. As an alternative approach, sequence-unspecific super-resolution imaging of histone H2B and of histone post-translational modifications was employed to visualize chromatin in fixed $[49,50]$, and recently also in living, cells $[12,51]$ (Fig. 2). These approaches revealed that nucleosomes transiently associate in groups. Since the genome and associated processes are inherently dynamic and many DNA-proteins as well as DNA-DNA contacts are transient, fixed cell studies naturally cannot capture this process and population assays represent a blurred picture over many cells. Time-resolved imaging is thus needed to appreciate the dynamic nature of the biological processes such as transcription in single cells. However, it is also evident that imaging specific sequences is necessary to place time-course data into a functional context. In the future, labeling strategies will need to be designed for fluorescence live-cell imaging to simultaneously 
observe structural changes of chromatin and its functional consequences simultaneously in the same cell (Fig. 1).

\section{Chromatin dynamics from single genes to the entire nucleus \\ Motion of individual chromatin loci is subdiffusive in living eukaryotic cells}

To gain insights into the dynamic behavior and spatio-temporal organization of chromosomes in live cells, distinct genomic sites can be labeled and tracked in real time (Fig. 2). Several methods have been developed to create a fluorescent signal distinguishable from background fluorescence [52]. Labeled loci can then be tracked over various length and time scales using single-particle tracking (SPT) approaches [53]. Gene editing tools contributed largely to visualize chromatin. The first method to tag chromatin loci and monitor their motion in real time used a chimeric DNA binding lac repressor - GFP fusion protein targeted to multiple repeats of operator binding sites [54, 55]. This approach showed that chromatin motion is constrained and anomalous and influenced by nuclear structures, cell cycle, and function [55-57]. A more innocuous system suited to study changes in chromatin motion in close vicinity of a genomic locus without disrupting its function is the ANCHOR/ParB DNA-labeling system. ANCHOR implants a short non-repetitive sequence near the gene of interest which triggers the accumulation of fluorescent ParB proteins [58, 59]. Several editing-free systems such as transcription activator-like effectors (TALE) $[60,61]$ and clustered regularly interspaced short palindromic repeats (CRISPR/inactive dCas9) [62,63] have also been used to visualize genomic loci [62-64]. These systems frequently suffer from poor SNR, but tracking of repetitive DNA sequences which provide a large number of sites confirmed that their motion is also constrained $[62,63,65]$. Most of these SPT studies concluded that the majority of mammalian interphase chromatin motion is subdiffusive [59, 66-68] and in some cases superdiffusive [69, 70].

\section{Motion of individual chromatin loci near genes changes in response to transcription activation in living eukaryotic cells}

The prevalence of inactive genes to localize near the nuclear periphery and active genes to prefer the nuclear interior suggests that those loci undergo long-range movements upon gene activation toward the nuclear interior [69]. This can however occur over hours or days, during development and differentiation, and cannot inform on the underlying physical properties of the chromatin fiber (for review see [71]). To determine how activating transcription influences the local motion of chromatin, a few recent studies have examined the behavior of tags inserted in the vicinity of genes. Combining the ANCHOR DNA-labeling system with MS2-labeled mRNAs enabled monitoring the motion of a single transgene under control of a hormone inducible endogenous promoter before and after transcription in the same cell [59]. While the motion of the single-gene domain remained subdiffusive, transcription initiation caused local confinement of the gene within seconds only when mRNA was produced in the analyzed cells [59]. Confinement was maintained during elongation by RNA polymerase II (RNAP II). These findings suggest that increased chromatin collisions and assembly of functional protein-DNA complexes during the steps of transcription reduce motion, coherent with an increase in local crowding (discussed below). An imaging system 
based on chimeric arrays of gRNA oligonucleotides (CARGO) to which dCas9-GFP fusion proteins bind was applied to monitor the Fgf5 enhancer and promotor loci in mouse embryonic stem cells (ESC) before and 4 days after inducing cellular differentiation [64]. In contrast to the study in mammary tumor cells by Germier et al. [59], the study by $\mathrm{Gu}$ et al. [64] reported that mobility increases at the enhancer and promoter of the target gene when its activation was inhibited [64]. The increase in calculated diffusion coefficients is explained by non-thermal agitation of chromatin domains, which may favor enhancer-promoter contacts as a result of the stochastic confrontations within the TADs [64]. However, the establishment of a TAD as defined by ensemble approaches does not necessarily insulate from inter-TAD contacts in single cells and is thus unlikely to promote enhanced contact frequencies upon enhanced dynamics. Contacts (within a physical distance of $<10 \mathrm{~nm}$ ) of two loci can thus only be reliably enhanced at loop bases due to the repeated extrusion of the region governing the loci of interest into loops, not because TAD formation promotes contacts of two loci within TADs at any time. It is also possible that changes in global chromatin organization in ES cells before and after 4 days of inducing differentiation have different dynamic properties independently of the motion of any individual gene or regulatory locus. This has yet to be tested. While recent studies of chromatin dynamic imaging at single nucleosome and global chromatin levels support the finding that chromatin is confined in transcriptionally active nuclei compared to cells treated with RNAP II inhibitors [16, 72], studying single gene motion in different cell lines (e.g., human cancer cells vs mouse ESC) using the same experimental setup and analysis method would be important.

\section{Chromatin dynamics are spatially partitioned in nuclear domains}

Early tools for visualizing chromatin within the entire nucleus either using the expression of fluorescent histones or by incorporating transfected fluorescent nucleotides during replication [73, 74] contributed later for studying the global dynamics of the genome. The alliance between photo-activated localization microscopy (PALM) and SPT is a powerful tool for quantifying chromatin dynamics at the single nucleosome level for sparse domains [16, 75]. Relying on the photoactivation of PAFP fluorophoretagged histone $\mathrm{H} 2 \mathrm{~B}$, this method tracks unbleached nucleosomes for up to $500 \mathrm{~ms}$ [75]. However, longer acquisition time is required for accurate analysis and in-depth understanding of the processes governing nucleosome dynamics at the physically and biologically relevant time scales. New organic fluorophore tags of DNA such as Hoechst 33342 and its far-red variants (silicon-rhodamine-Hoechst) [76, 77] have been introduced to circumvent phototoxicity and photobleaching that enabled analyzing the entire chromatin in vivo for up to $30 \mathrm{~s}[15,72]$.

Imaging abundant nuclear (macro-) molecules such as chromatin, transcription factors (TF), or RNA poses limitations on the application of common methods such as SPT to analyze their dynamics. Particle identification in a densely labeled environment is not always unique and may even be impossible due to the limited spatial resolution. As a complement to SPT for studying chromatin motion, raster image correlation spectroscopy, pair correlation analysis, and optical flow-based methods have been applied to quantify global chromatin motion in living cells $[15,67,78,79]$. The high-resolution diffusion mapping (Hi-D) method reconstructs trajectories at nanoscale precision 
across the entire nucleus simultaneously [72]. A Bayesian inference approach is used to infer types of diffusion for every single pixel. Consequently, the resulting highresolution maps of global chromatin diffusion provide biophysical parameters (type of diffusion, diffusion constant, anomalous exponent) of different nuclear domains in single living cells [72]. Chromatin domains spanning $0.3-3 \mu \mathrm{m}$ positioned in a mosaic-like manner were detected in the nuclear interior. These domains were seen to be remodeled in response to transcriptional activity. Strikingly, the dynamic properties of these patterns were uncoupled from chromatin density [72]. Emerging whole-chromatin super-resolution techniques could detect nanodomains, consisting of up to ten nucleosomes, as a small-scale structural entity (diameter $<100 \mathrm{~nm}$ ) of the genome $[49,51]$ and further developments enabled to determine whole-chromatin chromatin dynamics well below the diffraction limit to link structural changes of these entities to dynamics [12]. Mapping nuclear dynamics of dense molecules across the entire nucleus simultaneously instead of the isolated visualization of single loci opens new perspectives for our understanding of genome motion in the context of nuclear architecture.

\section{Spatio-temporal organization of transcriptional dynamics}

Transcription is a highly regulated and dynamic process [80] and is set up by transcription initiation controlled by binding and release of TFs to DNA sequences and transcriptional machineries [81, 82]. TF-binding kinetics and diffusion within the target DNA domains in live cells were originally determined using fluorescence recovery after photobleaching (FRAP) [81, 83]. Later, improving the signal to noise ratio (SNR) of labeled molecules enabled detecting and quantifying binding events of TFs to DNA in two [84] and three dimensions [85]. Fluorescence microscopy methods such as FRAP, fluorescence correlation spectroscopy (FCS) [86], SPT, and super-resolution microscopy have greatly contributed to uncover and quantify the variability of TF dynamics [87], including interactions with their genomic targets by measuring the residence times, on/off rates, and diffusion constants [80, 88]. The majority of these studies showed that the residence time of TFs at specific and non-specific binding sites varied by some orders of magnitude, with longer residence time for specific binding (milliseconds to a few seconds) than for non-specific binding (tens to hundreds of milliseconds) [84, 89]. The residence time of bound TFs may alter the spatio-temporal expression patterns, dynamics, and nuclear organization of TF-loaded loci in live cells [90]. Specifically, swift TF release is required for regulating expression patterns. Nonetheless, long residence times were recorded at some sites, making the process less tunable [80, 91, 92]. Long-time imaging of the TF Sox 2 and chromatin domains recorded jumps of Sox 2 between binding sites suggesting that kinetic chromatin domain structures facilitate transcription regulation at this locus in embryonic stem cell $[87,93]$. Yet, contacts between Sox2 and its enhancer, if any, were too short lived to be imaged [94] in an engineered system. Simultaneous imaging of labeled promoter, enhancer, and/or gene sequences in cells in which the local transcriptional state is known could in the future unequivocally characterize relative positions, possible contacts, and their frequencies between these transcriptional elements and sharpen our understanding of their coordination from transcription initiation to termination.

Transcription is not only regulated in time but depends largely also on the spatial organization of TFs and RNAP II [95]. Furthermore, transcription can modify the architecture and dynamics of DNA [96]. Nuclear gene positioning, packing, and looping 
of transcriptionally active loci are dynamic, granting proteins access to regulate the transcription processes at different levels [2, 97-99]. Likewise, the spatial distribution of TFs and RNAP II is highly imparted upon transcription initiation; for instance, RNAP II was found to cluster in transcription factories in early fluorescence and electron microscopy studies [100-104]. These transcription factories may form anchor points to which chromatin is tethered, thereby co-regulating the dynamics of chromatin and proteins that compose the factories [16]. Indeed, the motion of global chromatin and RNAP II correlates when examined at a nanoscale dynamic resolution and a time resolution of 5 fps [72], and chromatin dynamics are locally [59] and globally [16, 72] confined upon transcription. Furthermore, the formation of correlated chromatin domains could be linked to transcriptional activity. The correlated motion was decreased but not lost completely by blocking RNAP II activity [15, 67]. These results indicate that stopping transcription at early stages does not eliminate long-range contacts and does not dissolve transcription factories $[105,106]$. Spot tracking analysis of the evenskipped (eve) locus promotor and enhancer during transcription in live Drosophila embryos identified three topological states: an open state which is however inactively transcribed and a paired homie-homie state which can be both actively and inactively transcribed [107]. Accumulation of nascent mRNA indicates that transcription initiation transiently enhances the stability of the proximal configuration between enhancer and promoter and increases the gene's spatial compaction, consistent with hindered motion $[59,107,108]$. These examples highlight the role of transcription in shaping the hierarchical organization of mammalian genomes in the nuclear space as well as their dynamics.

\section{Mechanisms governing the dynamics of the genome during transcription}

Several mechanisms and models were proposed to explain the nature of the observed chromatin dynamics. Here, we discuss the most popular and experimentally-by fluorescence microscopy and biochemical methods-well-established principles.

\section{Liquid-liquid phase separation as a physical model to understand the regulation of gene expression}

Upon transcription initiation, hundreds of proteins have to reach a transcription start site in a highly coordinated manner [109]. Live-cell super-resolution imaging revealed that RNAP II engages transiently in transcription factories during transcription initiation [110, 111] (Fig. 3 (A)). The mechanism by which transcription factories form could be resolved by lattice light-sheet imaging in living cells: transcription factories behave like liquid condensates [112], membrane-less compartments, likely formed spontaneously by a liquid-liquid phase separation (LLPS) mechanism due to spatial concentration heterogeneities of the condensate components [113]. These findings found support [112, 114-119] in that the carboxyl-terminal domain (CTD) of RNAP II, an intrinsically disordered lowcomplexity region, can undergo cooperative LLPS in vitro [117]. The condensates are dissolved upon CTD phosphorylation [117], which is the same mechanism by which RNAP II is braced for transcription elongation [118, 120]. By controlling CTD phosphorylation, the contact duration between transcription factories and DNA may thus be regulated [110, 121]. This mechanism appears to be common to several other transcription factors in vivo [119], 


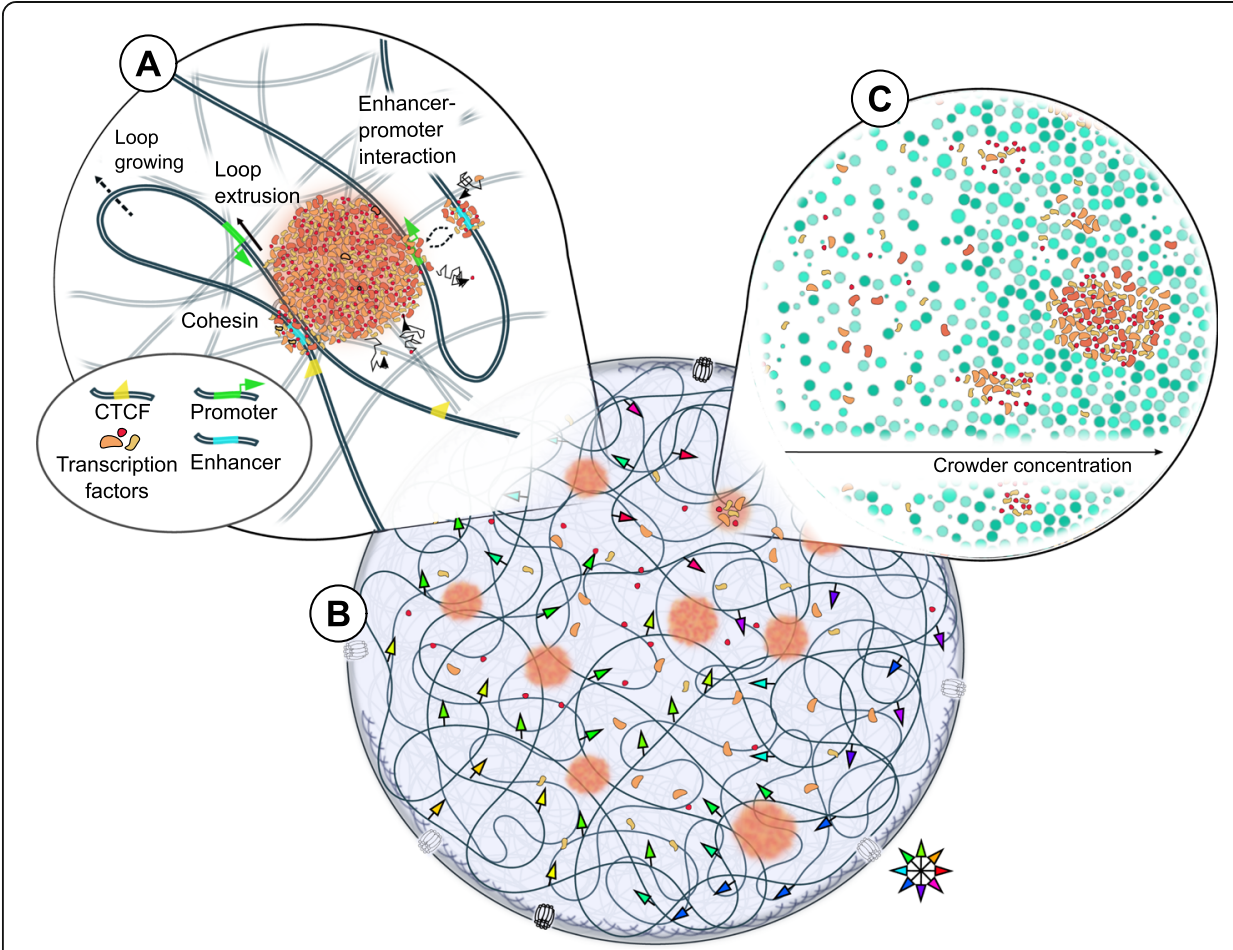

Fig. 3 Mechanisms for chromatin organization and dynamics during transcription. (A) The transcriptional hubs are formed by liquid-liquid phase separation of transcription factors, which in turn is mediated by the local crowding conditions. TFs binding to both enhancer and promoter mediate enhancer-promoter contacts by an effective attraction exerted by the LLPS property of transcription factories. Once transcription is initiated by these enhancer-promoter contacts, transcription elongation proceeds by reeling the transcribed gene body along the transcription factory. Loop extrusion by cohesin can additionally establish transient enhancer-promoter contacts, and the turnover time of cohesin and CTCF regulates the frequency of these contacts. Loop extrusion dynamics and the placement of (semi-) permeable border elements may thus regulate transcription. (B) The nucleus is sprinkled with transcription factories to which chromatin is tethered. The resulting network of transcriptional hubs restricts chromatin motion and induces a stiffness to chromatin, which is expressed in long-range correlations of chromatin dynamics (colored arrows). (C) The local molecular crowding reduction of chromatin mobility upon transcription. This transition is associated to high molecular crowding, eventually facilitating the formation of transcription factories to which chromatin is tethered

which led to the current view that transcription factories could be condensates in vivo, whose intrinsically disordered low-complexity sequence domains undergo liquid-liquid phase separation (LLPS) (Fig. 3 (A, B)).

Super-enhancers, clusters of putative enhancers in close proximity with unordinary high density of transcriptional co-activators binding [112, 115, 116], have shown the potential to form a nucleation point for LLPS, directed by master TFs [122]. The unusually high transcription activity of super-enhancers has to be "contained" within insulated neighborhoods, demarcated by Hi-C-defined TAD boundaries, in order to specifically activate their target gene [122]. As such, the local chromatin architecture appears to be vital to prevent ectopic gene activation.

LLPS does not only concern protein condensates such as transcription factories but may also interact with and actively shape the surrounding chromatin environment [123] (Fig. 3 (B)), in particular, at super-enhancers [124, 125]. For instance, the fusion of condensates minimizes their surface tension and deforms chromatin locally which may bring chromatin loci in the vicinity of each other [123]. Merging of condensates of 
TFs at promoters and enhancers could explain how these potentially distant genomic regions find each other (Fig. 3 (A)). Tethering of chromatin to transcriptional hubs could also account for reduced freedom of chromatin movement [16], and result in a stiffer DNA network, which is detected by spatially coherent motion [15, 67] (Fig. 3 (B)). Furthermore, chromatin itself can self-organize and phase-separate, consistent with entropic forces of polymers [126]. For instance, heterochromatin is preferentially found at the nuclear periphery and near nucleoli, and repressed genes are found buried inside nuclear compartments, while active genes and RNA-associated proteins preferentially lie on the surface of chromatin domains [51, 127]. Fluorescence microscopy is an excellent tool to detect and quantitatively study such LLPS-driven chromatin bodies and compartments [128].

\section{Molecular crowding drives chromatin dynamics, confinement, and function}

Molecular crowding significantly influences the diffusion of proteins within the nucleus and is a driver for transcriptional silencing within heterochromatin by phase separation $[4,129,130]$. Crowding affects the binding affinity of RNAP II on DNA [131, 132] such that in vitro transcription is markedly enhanced only when crowder volume fractions resemble those found in vivo $[133,134]$. Especially temporal changes in crowder density, as opposed to a commonly assumed steady-state crowder concentration, have been shown to be able to selectively up- or downregulate genes and could thus constitute an additional gene regulatory pathway for the cell [135]. Because the microenvironment of a chromatin locus relates to its dynamics [136-138], such crowding density fluctuations may be captured by varying chromatin dynamics over time. The reduction of chromatin mobility upon transcription suggests that this transition is related to a local accumulation of crowders, eventually facilitating phase separation of transcription factors to which chromatin is tethered [16, 72] (Fig. $3(\mathrm{C})$ ). Finally, it should be noted that not only proteins, but also chromatin itself, is a crowding agent. The observation that LLPS takes place in regions of low chromatin occupancy [123] could relate to the fact the local crowder concentrations can control the occurrence of LLPS. It is likely that several physical forces resulting from macromolecular crowding, chromatin compaction, and LLPS cooperate in order to spatially regulate transcription $[139,140]$.

\section{Coherent motion of chromatin depends on enzymatic activity}

Chromatin was shown to move coherently over several microns by live-cell imaging. This coherent motion was modulated by activating DNA processes [15, 67] (Fig. 3 (B)). Computational models of this motion suggest that chromatin is dynamically partitioned [5, 17]. Intriguingly, boundaries of coherently moving domains appeared uncoupled from domains of similar chromatin compaction, but not from transcription states [15, 72]. Self-organizing properties of active systems, propelled by ATP-driven proteins and promoted by the longscale correlation due to hydrodynamic interactions of the activity-induced motion, could be at the origin of coherence $[14,67,141-143]$. However, it should be pointed out that qualitatively similar findings can be yielded computationally when only chromatin chain conformation and epigenetic marks are taken into account [5, 17, 144]. Thus, the role of active chromatin remodelers remains to be further evaluated. Combining quantitative fluorescence imaging, $\mathrm{Hi}-\mathrm{C}$, and computational polymer modeling to study the mobility of yeast 
chromosomes demonstrated how heterogeneous binding patterns of proteins along the chromatin fiber could lead to thermodynamically driven self-organization and differential mobility [145]. Thus, while transcription or other energy-consuming processes can induce coherent motion, additional players shaping chromatin architecture and epigenetic landscapes should not be overlooked when interpreting live-cell imaging data of chromatin.

\section{Loop extrusion can create windows of opportunity for fine-tuning transcription}

The transcription factory model has been proposed to explain the mechanisms leading to genome folding [18, 93, 146, 147]. Binding of TFs to DNA induces a positive feedback loop by quickly re-binding dissolved TFs and recruiting new ones from the pool of freely diffusing TFs [18, 146] (Fig. 3 (A)). The resulting TF condensate is able to bridge different DNA regions and causes an effective bridging-induced attraction [146]. Merging of clusters at different DNA segments establishes chromatin loops, whose loop bases colocalize with TFs. This relatively simple mechanism was shown to be sufficient to recapitulate many features of chromatin structure established by $\mathrm{Hi}-\mathrm{C}$ such as rosettes and TADs $[148,149]$. This transcription factory model [18] supports the concept that transcription is an important driver of chromatin folding and dynamics $[1,15,16,72,96]$, but also takes into consideration chromatin contacts mediated by proteins which are unrelated or only distantly related to transcription.

The loop extrusion model [150-152] conceptualizes how chromosome structure emerges due to the extrusion of DNA loops from structural maintenance of chromosomes (SMC) proteins [153-157] as loop extruding factors. Based on a collaboration between the SMC protein cohesin and molecular boundary elements (CCCTC-binding factor (CTCF) proteins), the loop extrusion model recapitulates the hierarchical organization of chromosomes revealed by $\mathrm{Hi}-\mathrm{C}[158,159]$. Nevertheless, the model fails to reflect experimentally observed large-scale interactions [160], and it is now clear that phase separation mechanisms go hand in hand with loop extrusion [161].

In contrast, the transcription factory model poorly predicts details of interactions but correctly captures long-range contacts [160]. A combinatorial model consisting of the transcription factor and loop extrusion model faithfully reproduces many $\mathrm{Hi}-\mathrm{C}$ features suggesting that TFs and cohesin have complementary roles in genome organization [160]. Chromatin domain boundaries are often found at long and highly expressed genes, whose strength is driven by transcription length and transcription rate [162], and most chromatin contacts are established between active transcription units [163, 164]. Furthermore, increased contact frequencies in trans, at the expense of cis contacts, as revealed by ChiAPET [165], can be explained by the transcription factory model because this model is compatible with the idea that active genes on different chromosomes could be cotranscribed in the same transcription factory.

The loop extruding activity of cohesin was recently illustrated by in vitro experiments [157, 166, 167]. Given this mechanism, transient contacts between two genomic loci can be established, in particular enhancers and promoters, during the growth of the loop. The bulky transcriptional machinery is likely to influence the position of cohesinmediated DNA loops [96, 168] (Fig. 3 (A)). However, how cohesin interacts with single or multiple stalled or elongating transcription complexes remains to be interrogated experimentally. 
The loop extrusion and transcription factory models appear to complementarily explain how the genome is dynamically organized. Both models imply that transcription can influence the genome organization and vice versa.

\section{Future directions}

Sophisticated labeling techniques as well as super-resolution microscopy enabled direct visualization of nuclear processes at several length scales, mostly well below the diffraction limit. By incorporation of data derived from orthogonal approaches, a more and more complete picture of chromatin structure (blob forming), dynamics, and function emerges. However, it must be kept in mind that the nucleus is a technically challenging organelle to analyze. Its content is highly crowded, and there are only few wellstructured elements in the nucleus, which would facilitate the description of its interior by serving as reference points. Chromatin is a disordered, extraordinarily long, and confined biopolymer, which is constantly remodeled by a multitude of factors acting on it and that renders the analysis of chromatin and chromatin-associated processes highly complex.

Nevertheless, using advanced fluorescence imaging led us to a general picture in which transcription occurs in "transcription factories," condensates likely formed by liquid-liquid phase separation, to which chromatin is tethered and thus globally and locally constrained. Transcription appears in various aspects to be a key process to take into account in order to understand the dynamic chromatin landscape, even though other factors must also contribute [1].

However, the dependency between chromatin architecture and transcription regulation in vivo is a matter of debate. For instance, contacts between cis-regulatory elements precede gene activation during Drosophila development and remain regardless of the transcriptional state [169]. A few studies also found that enhancer-promoter proximity is not always indicative of the transcriptional state [94, 170]. Strikingly, auxin-inducible degradation of the insulator protein CTCF, which acts together with cohesin in human cells to shape chromatin loop domains/TADs, has only a mild impact on transcriptional deregulation [171], and auxin-induced degradation of cohesin has a similarly modest effect on transcription [172]. However, several lines of research demonstrated that the deletion of TAD boundaries can perturb transcription by interfering with ectopic enhancer-promoter contacts [173-175]. Genes which are deregulated upon loss of cohesin or CTCF are preferentially located at TAD boundaries, hinting toward a subtle regulatory role of factors shaping the genomic environment around cis-regulatory elements. Transient looping events by cohesin and/or TFs, which are likely not to be detectable by ensemble approaches such as $\mathrm{Hi}-\mathrm{C}$, could thus constitute a flexible mechanism by which genes can be both activated and repressed, for instance, as a response to stimuli.

To further elucidate how chromatin and transcription are regulated, four main challenges remain in the development of live-cell real-time imaging of nuclear processes and chromatin behavior: (i) sequence-specific labeling, (ii) multicolor imaging, (iii) super-resolution microscopy techniques to allow rapid imaging in three dimensions at a nanoscale resolution of densely distributed emitters, and (iv) improving computational tools that allow processing and visualization of a large pool of information in order to understand stochastic processes. 
At the single locus level, labeling technologies for tagging of multiple non-repetitive sequences to target specific chromatin domains for live-cell imaging need to be further improved to link chromatin dynamics to function. Applying a lattice light-sheet [176] illumination would be a technical solution to enhance image acquisition speed and decreasing phototoxicity $[177,178]$. In addition, machine learning algorithms offer a computational solution for processing and denoising of "low-quality" images acquired rapidly [12]. Multicolor live-cell imaging to directly visualize proteins and chromatin at the nanoscale and short time resolution will be a major feat.

\section{Supplementary Information}

The online version contains supplementary material available at https://doi.org/10.1186/s13059-020-02185-y.

Additional file 1. Review history.

Peer review information

Andrew Cosgrove and Kevin Pang were the primary editors of this article and managed its editorial process and peer review in collaboration with the rest of the editorial team.

Review history

The review history is available as Additional file 1.

\section{Authors' contributions}

H.A.S. conceptualized the project. H.A.S., R.B., and K.B. wrote the manuscript. All authors read and approved the final manuscript.

\section{Authors' information}

Twitter handles: @h_shaban (Haitham A. Shaban); @RomanBarth2 (Roman Barth); @kerstinbys (Kerstin Bystricky).

Funding

K.B. thanks the ANR Sinfonie grant for funding.

\section{Ethics approval and consent to participate}

Not applicable.

\section{Competing interests}

The authors declare that they have no competing interests.

\section{Author details}

${ }^{1}$ Spectroscopy Department, Physics Division, National Research Centre, Dokki, Cairo 12622, Egypt. ${ }^{2}$ Current Address: Institute of Bioengineering, Ecole Polytechnique Fédérale de Lausanne (EPFL), Lausanne, Switzerland. ${ }^{3}$ Department of Bionanoscience, Delft University of Technology, 2628 CJ Delft, The Netherlands. ${ }^{4}$ Laboratoire de Biologie Moléculaire Eucaryote (LBME), Centre de Biologie Intégrative (CBI), CNRS, UPS, University of Toulouse, 31062 Toulouse, France. ${ }^{5}$ Institut Universitaire de France (IUF), Paris, France.

Received: 20 March 2020 Accepted: 19 October 2020

Published online: 17 November 2020

\section{References}

1. van Steensel B, Furlong EEM. The role of transcription in shaping the spatial organization of the genome. Nat Rev Mol Cell Biol. 2019;20(6):327-37.

2. Gibcus JH, Dekker J. The hierarchy of the 3D genome. Mol Cell. 2013;49(5):773-82.

3. Lanctôt C, Cheutin T, Cremer M, Cavalli G, Cremer T. Dynamic genome architecture in the nuclear space: regulation of gene expression in three dimensions. Nat Rev Genet. 2007:8(2):104-15.

4. Bancaud A, Huet S, Daigle N, Mozziconacci J, Beaudouin J, Ellenberg J. Molecular crowding affects diffusion and binding of nuclear proteins in heterochromatin and reveals the fractal organization of chromatin. EMBO J. 2009;28:3785-98.

5. Liu L, Shi G, Thirumalai D, Hyeon C. Chain organization of human interphase chromosome determines the spatiotemporal dynamics of chromatin loci. PLoS Comput Biol. 2018;14(12):e1006617.

6. $\quad$ Dekker J, Rippe K, Dekker M, Kleckner N. Capturing chromosome conformation. Science. 2002;295(5558):1306-11.

7. Lieberman-Aiden E, van Berkum NL, Williams L, Imakaev M, Ragoczy T, Telling A, et al. Comprehensive mapping of longrange interactions reveals folding principles of the human genome. Science. 2009;326(5950):289-93.

8. Shaban HA, Seeber A. Monitoring the spatio-temporal organization and dynamics of the genome. Nucleic Acids Res. 2020;48(7):3423-34

9. Agbleke AA, Amitai A, Buenrostro JD, Chakrabarti A, Chu L, Hansen AS, et al. Advances in chromatin and chromosome research: perspectives from multiple fields. Mol Cell. 2020;79(6):881-901.

10. Boettiger A, Murphy S. Advances in chromatin imaging at kilobase-scale resolution. Trends Genet. 2020;36(4):273-87. 
11. Lakadamyali M, Cosma MP. Visualizing the genome in high resolution challenges our textbook understanding. Nat Methods. 2020;17(4):371-9.

12. Barth R, Bystricky K, Shaban HA. Coupling chromatin structure and dynamics by live super-resolution imaging. Sci Adv. American Association for the Advancement of Science; 2020;6(27):eazz2196.

13. Barth R, Fourel G, Shaban HA. Dynamics as a cause for the nanoscale organization of the genome. Nucleus. 2020;11:83-98.

14. Saintillan D, Shelley MJ, Zidovska A. Extensile motor activity drives coherent motions in a model of interphase chromatin. Proc Natl Acad Sci U S A. 2018;115(45):11442-7.

15. Shaban HA, Barth R, Bystricky K. Formation of correlated chromatin domains at nanoscale dynamic resolution during transcription. Nucleic Acids Res. 2018;46(13):e77. https://doi.org/10.1093/nar/gky269.

16. Nagashima R, Hibino K, Ashwin SS, Babokhov M, Fujishiro S, Imai R, et al. Single nucleosome imaging reveals loose genome chromatin networks via active RNA polymerase II. J Cell Biol. 2019;218(5):1511-30.

17. Di Pierro M, Potoyan DA, Wolynes PG, Onuchic JN. Anomalous diffusion, spatial coherence, and viscoelasticity from the energy landscape of human chromosomes. Proc Natl Acad Sci. 2018;115(30):7753-8.

18. Cook PR, Marenduzzo D. Transcription-driven genome organization: a model for chromosome structure and the regulation of gene expression tested through simulations. Nucleic Acids Res. 2018;46(19):9895-906.

19. Tortora MM, Salari H, Jost D. Chromosome dynamics during interphase: a biophysical perspective. Curr Opin Genet Dev. 2020;61:37-43.

20. Dixon JR, Selvaraj S, Yue F, Kim A, Li Y, Shen Y, et al. Topological domains in mammalian genomes identified by analysis of chromatin interactions. Nature. 2012;485:376-80.

21. Nora EP, Lajoie BR, Schulz EG, Giorgetti L, Okamoto I, Servant N, et al. Spatial partitioning of the regulatory landscape of the X-inactivation centre. Nature. 2012;485:381-5.

22. Fortin JP, Hansen KD. Reconstructing A/B compartments as revealed by Hi-C using long-range correlations in epigenetic data. Genome Biol. 2015;16(1):180

23. Nagano T, Lubling Y, Stevens TJ, Schoenfelder S, Yaffe E, Dean W, et al. Single-cell Hi-C reveals cell-to-cell variability in chromosome structure. Nature. 2013;502:59-64.

24. Nagano T, Lubling Y, Várnai C, Dudley C, Leung W, Baran Y, et al. Cell-cycle dynamics of chromosomal organization at single-cell resolution. Nature. 2017;547:61-7.

25. Flyamer IM, Gassler J, Imakaev M, Brandão HB, Ulianov SV, Abdennur N, et al. Single-nucleus Hi-C reveals unique chromatin reorganization at oocyte-to-zygote transition. Nature. 2017;544(7648):110-4.

26. Stevens TJ, Lando D, Basu S, Liam P, Cao Y, Lee SF, et al. 3D structures of individual mammalian genomes studied by single-cell Hi-C. Nature Nature Publishing Group. 2017;544:59-64.

27. Cattoni DI, Gizzi AMC, Georgieva M, Di Stefano M, Valeri A, Chamousset D, et al. Single-cell absolute contact probability detection reveals chromosomes are organized by multiple low-frequency yet specific interactions. Nat Commun. 2017; $8(1): 1-0$.

28. Fudenberg G, Imakaev M. FISH-ing for captured contacts: towards reconciling FISH and 3C. Nat Methods. 2017;14:673-8.

29. Fraser J, Williamson I, Bickmore WA, Dostie J. An overview of genome organization and how we got there: from FISH to Hi-C. Microbiol Mol Biol Rev. 2015;79(3):347-72.

30. Giorgetti L, Heard E. Closing the loop: 3C versus DNA FISH. Genome Biol. 2016;17(1):1-9.

31. Wang S, Su JH, Beliveau BJ, Bintu B, Moffitt JR, Wu CT, et al. Spatial organization of chromatin domains and compartments in single chromosomes. Science (80-). 2016;353:598-602.

32. Williamson I, Berlivet S, Eskeland R, Boyle S, Illingworth RS, Paquette D, et al. Spatial genome organization: contrasting views from chromosome conformation capture and fluorescence in situ hybridization. Genes Dev. 2014;28(24):2778-91.

33. Shachar S, Voss TC, Pegoraro G, Sciascia N, Misteli T. Identification of gene positioning factors using high-throughput imaging mapping. Cell. 2015;162(4):911-23

34. Finn EH, Pegoraro G, Brandão HB, Valton AL, Oomen ME, Dekker J, et al. Extensive heterogeneity and intrinsic variation in spatial genome organization. Cell. 2019;176:1502-1515.e10.

35. Su J-H, Zheng P, Kinrot SS, Bintu B, Zhuang X. Genome-scale imaging of the 3D organization and transcriptional activity of chromatin. Cell. 2020;182(6):1641-59.

36. Kumari K, Duenweg B, Padinhateeri R, Prakash JR. Computing 3D chromatin configurations from contact probability maps by inverse Brownian dynamics. Biophys J. 2020;118(9):2193-2208.

37. Fudenberg G, Mirny LA. Higher-order chromatin structure: bridging physics and biology. Curr Opin Genet Dev Elsevier Ltd. 2012;22:115-24.

38. Van de Corput MPC, De Boer E, Knoch TA, Van Cappellen WA, Quintanilla A, Ferrand L, et al. Super-resolution imaging reveals three-dimensional folding dynamics of the $\beta$-globin locus upon gene activation. J Cell Sci. 2012;125(19):4630-9.

39. Maass PG, Barutcu AR, Shechner DM, Weiner CL, Melé M, Rinn JL. Spatiotemporal allele organization by allele-specific CRISPR live-cell imaging (SNP-CLING). Nat Struct Mol Biol. 2018;25(2):176-84.

40. Wang H, Xu X, Nguyen CM, Liu Y, Gao Y, Lin X, et al. CRISPR-mediated programmable 3D genome positioning and nuclear organization. Cell. 2018;175(5):1405-17.

41. Bintu B, Mateo LJ, Su JH, Sinnott-Armstrong NA, Parker M, Kinrot S, et al. Super-resolution chromatin tracing reveals domains and cooperative interactions in single cells. Science. 2018;362(6413).

42. Cardozo Gizzi AM, Cattoni DI, Fiche JB, Espinola SM, Gurgo J, Messina O, et al. Microscopy-based chromosome conformation capture enables simultaneous visualization of genome organization and transcription in intact organisms. Mol Cell. 2019;74:212-222.e5.

43. Mateo LJ, Murphy SE, Hafner A, Cinquini IS, Walker CA, Boettiger AN. Visualizing DNA folding and RNA in embryos at single-cell resolution. Nature. 2019;568(7750):49-54.

44. Larson DR. Structure and function in Drosophila chromosomes: visualizing topological domains. Mol Cell. 2019;74(1):3-4.

45. Lubeck E, Cai L. Single-cell systems biology by super-resolution imaging and combinatorial labeling. Nat Methods. 2012; 9(7):743-8,

46. Chen KH, Boettiger AN, Moffitt JR, Wang S, Zhuang X. Spatially resolved, highly multiplexed RNA profiling in single cells. Science. 2015;348(6233). 
47. Krietenstein N, Abraham S, Venev SV, Abdennur N, Gibcus J, Hsieh THS, et al. Ultrastructural details of mammalian chromosome architecture. Mol Cell. 2020;78(3):554-565.e7.

48. Hsieh THS, Weiner A, Lajoie B, Dekker J, Friedman N, Rando OJ. Mapping nucleosome resolution chromosome folding in yeast by micro-C. Cell. 2015;162(1):108-19.

49. Ricci MA, Manzo C, García-Parajo MF, Lakadamyali M, Cosma MP. Chromatin fibers are formed by heterogeneous groups of nucleosomes in vivo. Cell. 2015;160:1145-58.

50. Xu J, Ma H, Jin J, Uttam S, Fu R, Huang Y, et al. Super-resolution imaging of higher-order chromatin structures at different epigenomic states in single mammalian cells. Cell Rep. 2018;24(4):873-82

51. Miron E, Oldenkamp R, Pinto DMS, Brown JM, Faria AR, Shaban HA, et al. Chromatin arranges in filaments of blobs with nanoscale functional zonation.Science Advances. 2020; 6(39):eaba8811.

52. Bancaud A, Gadal O, Bystricky K. Capturing chromosome structural properties from their spatial and temporal fluctuations. Epigenetics and Systems Biology. Academic Press, 2017. 239-263.

53. Seeber A, Hauer MH, Gasser SM. Chromosome dynamics in response to DNA damage. Annu Rev Genet. 2018;52:295319.

54. Robinett CC, Straight A, Li G, Willhelm C, Sudlow G, Murray A, et al. In vivo localization of DNA sequences and visualization of large-scale chromatin organization using lac operator/repressor recognition. J Cell Biol. 1996;135(6):1685-700.

55. Marshall WF, Straight A, Marko JF, Swedlow J, Dernburg A, Belmont A, et al. Interphase chromosomes undergo constrained diffusional motion in living cells. Curr Biol. 1997;7(12):930-9.

56. Heun P. Chromosome dynamics in the yeast interphase nucleus. Science. 2001;294(5549):2181-6.

57. Cabal GG, Genovesio A, Rodriguez-Navarro S, Zimmer C, Gadal O, Lesne A, et al. SAGA interacting factors confine subdiffusion of transcribed genes to the nuclear envelope. Nature. 2006;441:770-3.

58. Saad H, Gallardo F, Dalvai M, Tanguy-le-Gac N, Lane D, Bystricky K. DNA dynamics during early double-strand break processing revealed by non-intrusive imaging of living cells. PLOS Genet. 2014;10(3):e1004187.

59. Germier T, Kocanova S, Walther N, Elien Bancaud A, Shaban HAHA, Sellou H, et al. Real-time imaging of a single gene reveals transcription-initiated local confinement. Biophys J. 2017;113:1383-94.

60. Miyanari Y, Ziegler-Birling C, Torres-Padilla M-E. Live visualization of chromatin dynamics with fluorescent TALEs. Nat Struct Mol Biol. 2013;20(11):1321-4.

61. Ma H, Reyes-Gutierrez P, Pederson T. Visualization of repetitive DNA sequences in human chromosomes with transcription activator-like effectors. Proc Natl Acad Sci. 2013;110(52):21048-53.

62. Chen B, Gilbert LA, Cimini BA, Schnitzbauer J, Zhang W, Li GW, et al. Dynamic imaging of genomic loci in living human cells by an optimized CRISPR/Cas system. Cell. 2013;155:1479-91.

63. Ma H, Naseri A, Reyes-Gutierrez P, Wolfe SA, Zhang S, Pederson T. Multicolor CRISPR labeling of chromosomal loci in human cells. Proc Natl Acad Sci U S A. 2015;112(10):3002-7.

64. Gu B, Swigut T, Spencley A, Bauer MR, Chung M, Meyer T, et al. Transcription-coupled changes in nuclear mobility of mammalian cis-regulatory elements. Science. 2018;359(6379):1050-5.

65. Bronshtein I, Kepten E, Kanter I, Berezin S, Lindner M, Redwood AB, et al. Loss of lamin A function increases chromatin dynamics in the nuclear interior. Nat Commun. 2015;6(1):1-9.

66. Chubb JR, Boyle S, Perry P, Bickmore WA. Chromatin motion is constrained by association with nuclear compartments in human cells. Curr Biol. 2002;12:439-45.

67. Zidovska A, Weitz DA, Mitchison TJ. Micron-scale coherence in interphase chromatin dynamics. Proc Natl Acad Sci U S A. 2013;110:15555-60.

68. Shinkai S, Nozaki T, Maeshima K, Togashi Y. Dynamic nucleosome movement provides structural information of topological chromatin domains in living human cells. PLoS Comput Biol. 2016;12(10):e1005136.

69. Chuang $\mathrm{CH}$, Carpenter AE, Fuchsova B, Johnson T, de Lanerolle P, Belmont AS. Long-range directional movement of an interphase chromosome site. Curr Biol. 2006;16:825-31.

70. Levi V, Ruan Q, Plutz M, Belmont AS, Gratton E. Chromatin dynamics in interphase cells revealed by tracking in a twophoton excitation microscope. Biophys J. 2005;89:4275-85.

71. Chuang $\mathrm{CH}$, Belmont AS. Moving chromatin within the interphase nucleus-controlled transitions? In Seminars in cell \& developmental biology 2007 (Vol. 18, No. 5, pp. 698-706). Academic Press.

72. Shaban HA, Barth R, Recoules L, Bystricky K. Hi-D: nanoscale mapping of nuclear dynamics in single living cells. Genome Biol. 2020;21:1-21.

73. Ellenberg J, Lippincott-Schwartz J, Presley JF. Dual-colour imaging with GFP variants. Trends Cell Biol. 1999;9(2):52-6.

74. Salic A, Mitchison TJ. A chemical method for fast and sensitive detection of DNA synthesis in vivo. Proc Natl Acad Sci U S A. 2008;105(7):2415-20.

75. Nozaki T, Imai R, Tanbo M, Nagashima R, Tamura S, Tani T. Dynamic organization of chromatin domains revealed by super-resolution live-cell imaging. Mol Cell. 2017;10:1-12.

76. Lukinavičius G, Blaukopf C, Pershagen E, Schena A, Derivery E, Gonzalez-gaitan M, et al. A far-red DNA stain for live-cell nanoscopy. Nat Commun. 2015;61:3-5.

77. Bucevičius J, Keller-Findeisen J, Gilat T, Hell SW, Lukinavičius G. Rhodamine-Hoechst positional isomers for highly efficient staining of heterochromatin. Chem Sci. 2019;10(7):1962-70

78. Scipioni L, Di Bona M, Vicidomini G, Diaspro A, Lanzanò L. Local raster image correlation spectroscopy generates highresolution intracellular diffusion maps. Commun Biol. 2018;1:10.

79. Hinde E, Cardarelli F, Digman MA, Gratton E. In vivo pair correlation analysis of EGFP intranuclear diffusion reveals DNAdependent molecular flow. Proc Natl Acad Sci. 2010;107:16560-5.

80. Liu Z, Tjian R. Visualizing transcription factor dynamics in living cells. J. Cell Biol. 2018;217(4):1181-91.

81. McNally JC, Müller WG, Walker D, Wolford R, Hager GL. The glucocorticoid receptor: rapid exchange with regulatory sites in living cells. Science. 2000;287:1262-5.

82. Zhao ZW, White MD, Bissiere S, Levi V, Plachta N. Quantitative imaging of mammalian transcriptional dynamics: from single cells to whole embryos. BMC Biol. 2016;14(1):1-11.

83. Stenoien DL, Patel K, Mancini MG, Dutertre M, Smith CL, O'Malley BW, et al. FRAP reveals that mobility of oestrogen receptor-a is ligand- and proteasome-dependent. Nat Cell Biol. 2001;3:15-23. 
84. Gebhardt JCM, Suter DM, Roy R, Zhao ZW, Chapman AR, Basu S, et al. Single-molecule imaging of transcription factor binding to DNA in live mammalian cells. Nat Methods. 2013;10:421-6.

85. Shechtman $Y$, Gustavsson A-K, Petrov PN, Dultz E, Lee MY, Weis K, et al. Observation of live chromatin dynamics in cells via 3D localization microscopy using tetrapod point spread functions. Biomed Opt Express. 2017;8:5735.

86. Michelman-Ribeiro A, Mazza D, Rosales T, Stasevich TJ, Boukari H, Rishi V, et al. Direct measurement of association and dissociation rates of DNA binding in live cells by fluorescence correlation spectroscopy. Biophys J. 2009;97:337-46.

87. Chen J, Zhang Z, Li L, Chen BC, Revyakin A, Hajj B, et al. Single-molecule dynamics of enhanceosome assembly in embryonic stem cells. Cell. 2014;156:1274-85.

88. Suter DM. Transcription factors and DNA play hide and seek. Trends Cell Biol. 2020;30(6):491-500.

89. Vukojević V, Papadopoulos DK, Terenius L, Gehring WJ, Rigler R. Quantitative study of synthetic Hox transcription factorDNA interactions in live cells. Proc Natl Acad Sci U S A. 2010;107(9):4093-8.

90. Raccaud M, Friman ET, Alber AB, Agarwal H, Deluz C, Kuhn T, et al. Mitotic chromosome binding predicts transcription factor properties in interphase. Nat Commun. 2019;10(1):1-6.

91. Clauß K, Popp AP, Schulze L, Hettich J, Reisser $M$, Torres $L E$, et al. DNA residence time is a regulatory factor of transcription repression. Nucleic Acids Res. 2017;45(19):11121-30.

92. Friman ET, Deluz C, Meireles-Filho ACA, Govindan S, Gardeux V, Deplancke B, et al. Dynamic regulation of chromatin accessibility by pluripotency transcription factors across the cell cycle. Elife. 2019;8:e50087.

93. Liu H, Dong P, loannou MS, Li L, Shea J, Pasolli HA, et al. Visualizing long-term single-molecule dynamics in vivo by stochastic protein labeling. Proc Natl Acad Sci. 2018;115:343-8.

94. Alexander JM, Guan J, Li B, Maliskova L, Song M, Shen Y, et al. Live-cell imaging reveals enhancer-dependent sox2 transcription in the absence of enhancer proximity. Elife. 2019;8:e41769.

95. Ferreira J, Paolella G, Ramos C, Lamond Al. Spatial organization of large-scale chromatin domains in the nucleus: a magnified view of single chromosome territories. J Cell Biol. 1997;139:1597-610.

96. Heinz S, Texari L, Hayes MGB, Urbanowski M, Chang MW, Givarkes N, et al. Transcription elongation can affect genome 3D structure. Cell. 2018;174(6):1522-36.

97. Dekker J, Mirny L. The 3D genome as moderator of chromosomal communication. Cell. 2016;164:1110-21.

98. Fraser P. Transcriptional control thrown for a loop. Curr Opin Genet Dev. 2006;16(5):490-5.

99. Hübner MR, Spector DL. Chromatin dynamics. Annu Rev Biophys. 2010:39:471-89.

100. Jackson DA, Hassan AB, Errington RJ, Cook PR. Visualization of focal sites of transcription within human nuclei. EMBO J. 1993;12:1059-65.

101. Wansink DG, Schul W, Van der Kraan I, Van Steensel B, Van Driel R, De Jong L. Fluorescent labeling of nascent RNA reveals transcription by RNA polymerase II in domains scattered throughout the nucleus. J Cell Biol. 1993;122:283-93.

102. Ghamari A, van de Corput MPC, Thongjuea S, van Cappellen WA, van ljcken W, van Haren J, et al. In vivo live imaging of RNA polymerase II transcription factories in primary cells. Genes Dev, 2013;27:767-777.

103. Cook PR. The organization of replication and transcription. Science. 1999;284(5421):1790-5.

104. Papantonis A, Cook PR. Transcription factories: genome organization and gene regulation. Chem Rev. 2013;113(11):8683-705.

105. Palstra RJ, Simonis M, Klous P, Brasset E, Eijkelkamp B, de Laat W. Maintenane of long-ranage DNA interactions after inhibition of ongoing RNA polymerase II transcription. PLoS One. 2008;3(2):e1661.

106. Mitchell JA, Fraser P. Transcription factories are nuclear subcompartments that remain in the absence of transcription. Genes Dev. 2008;22(1):20-5.

107. Chen H, Levo M, Barinov L, Fujioka M, Jaynes JB, Gregor T. Dynamic interplay between enhancer-promoter topology and gene activity. Nat Genet. 2018;50(9):1296-303.

108. Tsai A, Alves MR, Crocker J. Multi-enhancer transcriptional hubs confer phenotypic robustness. Elife. 2019;8:e45325.

109. Jonkers I, Lis JT. Getting up to speed with transcription elongation by RNA polymerase II. Nat Rev Mol Cell Biol. 2015; 16(3):167-77.

110. Cisse II, Izeddin I, Causse SZ, Boudarene L, Senecal A, Muresan L, et al. Real-time dynamics of RNA polymerase II clustering in live human cells. Science. 2013;341:664-7.

111. Chen X, Wei M, Zheng MM, Zhao J, Hao H, Chang L, et al. Study of RNA polymerase II clustering inside live-cell nuclei using Bayesian nanoscopy. ACS Nano. 2016;10:2447-54.

112. Cho WK, Spille JH, Hecht M, Lee C, Li C, Grube V, et al. Mediator and RNA polymerase II clusters associate in transcription-dependent condensates. Science (80-). 2018;361:412-5.

113. Alberti S, Gladfelter A, Mittag T. Considerations and challenges in studying liquid-liquid phase separation and biomolecular condensates. Cell. 2019;176(3):419-34.

114. Banani SF, Lee HO, Hyman AA, Rosen MK. Biomolecular condensates: organizers of cellular biochemistry. Nat Rev Mol Cell Biol. 2017;18(5):285-98.

115. Boija A, Klein IA, Sabari BR, Dall'Agnese A, Coffey EL, Zamudio AV, et al. Transcription factors activate genes through the phase-separation capacity of their activation domains. Cell. 2018;175(7):1842-55.

116. Sabari BR, Dall'Agnese A, Boija A, Klein IA, Coffey EL, Shrinivas K, et al. Coactivator condensation at super-enhancers links phase separation and gene control. Science. 2018;361(6400).

117. Boehning M, Dugast-Darzacq C, Rankovic M, Hansen AS, Yu T, Marie-Nelly H, et al. RNA polymerase II clustering through carboxy-terminal domain phase separation. Nat Struct Mol Biol. 2018;25(9):833-40.

118. Kwon I, Kato M, Xiang S, Wu L, Theodoropoulos P, Mirzaei H, et al. Phosphorylation-regulated binding of RNA polymerase II to fibrous polymers of low-complexity domains. Cell. 2013;155:1049-60.

119. Chong S, Dugast-Darzacq C, Liu Z, Dong P, Dailey GM, Cattoglio C, et al. Imaging dynamic and selective low-complexity domain interactions that control gene transcription. Science. 2018;361(6400).

120. Allen BL, Taatjes DJ. The mediator complex: a central integrator of transcription. Nat Rev Mol Cell Biol. 2015;16(3):155-66.

121. Cho WK, Jayanth N, English BP, Inoue T, Andrews JO, Conway W, et al. RNA polymerase II cluster dynamics predict mRNA output in living cells. Elife. 2016:5:e13617.

122. Wang X. Cairns MJ. Nucleic Acids Res: Yan J. Super-enhancers in transcriptional regulation and genome organization; 2019:47(22):11481-96. 
123. Shin $Y$, Chang YC, Lee DSW, Berry J, Sanders DW, Ronceray $P$, et al. Liquid nuclear condensates mechanically sense and restructure the genome. Cell. 2018;175(6):1481-91.

124. Novo CL, Javierre BM, Cairns J, Segonds-Pichon A, Wingett SW, Freire-Pritchett $P$, et al. Long-range enhancer interactions are prevalent in mouse embryonic stem cells and are reorganized upon pluripotent state transition. Cell Rep. 2018; 22(10):2615-27.

125. Ryu J, Kim H, Yang D, Lee AJ, Jung I. A new class of constitutively active super-enhancers is associated with fast recovery of 3D chromatin loops. BMC Bioinformatics. 2019;20(3):25-36.

126. Cook PR, Marenduzzo D. Entropic organization of interphase chromosomes. J Cell Biol. 2009;186:825-34.

127. Cremer T, Cremer M, Hübner B, Strickfaden H, Smeets D, Popken J, et al. The 4D nucleome: evidence for a dynamic nuclear landscape based on co-aligned active and inactive nuclear compartments. FEBS Lett. 2015;9(20):2931-43.

128. Walther N, Hossain MJ, Politi AZ, Koch B, Kueblbeck M, Odegard-fougner $\varnothing$, et al. A quantitative map of human condensins provides new insights into mitotic chromosome architecture. J Cell Biol. 2018;217(7):2309-28.

129. Fourel G, Magdinier F, Gilson É. Insulator dynamics and the setting of chromatin domains. BioEssays. 2004;26(5):523-32.

130. Strom AR, Emelyanov AV, Mir M, Fyodorov DV, Darzacq X, Karpen GH. Phase separation drives heterochromatin domain formation. Nature. 2017:547(7662):241-5.

131. Sokolova E, Spruijt E, Hansen MMK, Dubuc E, Groen J, Chokkalingam V, et al. Enhanced transcription rates in membranefree protocells formed by coacervation of cell lysate. Proc Natl Acad Sci U S A. 2013;110(29):11692-7.

132. Ge X, Luo D, Xu J. Cell-free protein expression under macromolecular crowding conditions. PLoS One. 2011;6(12): e28707.

133. Chung SY, Lerner E, Jin Y, Kim S, Alhadid Y, Grimaud LW, et al. The effect of macromolecular crowding on single-round transcription by Escherichia coli RNA polymerase. Nucleic Acids Res. 2019;47(3):1440-50.

134. Matsuda H, Putzel GG, Backman V, Szleifer I. Macromolecular crowding as a regulator of gene transcription. Biophys J. 2014;106(8):1801-10.

135. Shim AR, Nap RJ, Huang K, Almassalha LM, Matusda H, Backman V, et al. Dynamic crowding regulates transcription. BiophysJ. 2019;1 18(9):2117-29.

136. Socol M, Wang R, Jost D, Carrivain P, Vaillant C, Le Cam E, et al. Rouse model with transient intramolecular contacts on a timescale of seconds recapitulates folding and fluctuation of yeast chromosomes. Nucleic Acids Res. 2019;47(12):6195207.

137. Amitai A. Chromatin configuration affects the dynamics and distribution of a transiently interacting protein. Biophys $J$. 2018;114(4):766-71.

138. Weber SC, Spakowitz AJ, Theriot JA. Bacterial chromosomal loci move subdiffusively through a viscoelastic cytoplasm. Phys Rev Lett. 2010;104(23):238102.

139. Kim JS, Backman V, Szleifer I. Crowding-induced structural alterations of random-loop chromosome model. Phys Rev Lett. 2011;106(16):168102.

140. Kang H, Pincus PA, Hyeon C, Thirumalai D. Effects of macromolecular crowding on the collapse of biopolymers. Phys Rev Lett. 2015;114(6):068303.

141. Guérin T, Prost J, Martin P, Joanny JF. Coordination and collective properties of molecular motors: theory. Curr Opin Cell Biol. 2010;22(1):14-20

142. Holzbaur EL, Goldman YE. Coordination of molecular motors: from in vitro assays to intracellular dynamics. Curr Opin Cell Biol. 2010;22(1):4-13.

143. Put S, Sakaue T, Vanderzande C. Active dynamics and spatially coherent motion in chromosomes subject to enzymatic force dipoles. Phys Rev E. 2019;99(3):032421.

144. Di Pierro M, Zhang B, Aiden EL, Wolynes PG, Onuchic JN. Transferable model for chromosome architecture. Proc Natl Acad Sci. 2016;113(43):12168-73.

145. Sewitz SA, Fahmi Z, Aljebali L, Bancroft J, Brustolini OJB, Saad H, et al. Heterogeneous chromatin mobility derived from chromatin states is a determinant of genome organisation in S. cerevisiae. bioRxiv [Internet]. 2017;106344. Available from: https://www.biorxiv.org/content/early/2017/03/02/106344.full.pdf+html.

146. Brackley CA, Taylor S, Papantonis A, Cook PR, Marenduzzo D. Nonspecific bridging-induced attraction drives clustering of DNA-binding proteins and genome organization. Proc Natl Acad Sci. 2013;110:E3605-11.

147. Liu Z, Legant WR, Chen BC, Li L, Grimm JB, Lavis LD, et al. 3D imaging of Sox2 enhancer clusters in embryonic stem cells. Elife. 2014;3:e04236.

148. Brackley CA, Johnson J, Kelly S, Cook PR, Marenduzzo D. Simulated binding of transcription factors to active and inactive regions folds human chromosomes into loops, rosettes and topological domains. Nucleic Acids Res. 2016;44:3503-12.

149. Barbieri M, Chotalia M, Fraser J, Lavitas LM, Dostie J, Pombo A, et al. Complexity of chromatin folding is captured by the strings and binders switch model. Proc Natl Acad Sci U S A. 2012;109(40):16173-8.

150. Alipour E, Marko JF. Self-organization of domain structures by DNA-loop-extruding enzymes. Nucleic Acids Res. 2012;40: $11202-12$.

151. Riggs AD. DNA methylation and late replication probably aid cell memory, and type I DNA reeling could aid chromosome folding and enhancer function. Philos Trans R Soc Lond Ser B Biol Sci. 1990;326(1235):285-97.

152. Nasmyth K. Disseminating the genome: joining, resolving, and separating sister chromatids during mitosis and meiosis. Annu Rev Genet. 2001;35(1):673-745.

153. Ganji M, Shaltiel IA, Bisht S, Kim E, Kalichava A, Haering CH, et al. Real-time imaging of DNA loop extrusion by condensin. Science. 2018;360(6384):102-5.

154. Stefan Golfier, Thomas Quail, Hiroshi Kimura JB. Cohesin and condensin extrude loops in a cell-cycle dependent manner. bioRxiv. 2019.

155. Kong M, Cutts EE, Pan D, Beuron F, Kaliyappan T, Xue C, et al. Human condensin I and II drive extensive ATP-dependent compaction of nucleosome-bound DNA. Mol Cell. 2020;79(1):99-114.e9.

156. Davidson IF, Bauer B, Goetz D, Tang W, Wutz G, Peters J-M. DNA loop extrusion by human cohesin. Science. 2019; 366(6471):1338-45.

157. Kim Y, Shi Z, Zhang H, Finkelstein IJ, Yu H. Human cohesin compacts DNA by loop extrusion. Science. 2019;366(6471): 1345-9. 
158. Fudenberg G, Imakaev M, Lu C, Goloborodko A, Abdennur N, Mirny LA. Formation of chromosomal domains by loop extrusion. Cell Rep. 2016;15(9):2038-49.

159. Sanborn AL, Rao SSP, Huang S-C, Durand NC, Huntley MH, Jewett Al, et al. Chromatin extrusion explains key features of loop and domain formation in wild-type and engineered genomes. Proc Natl Acad Sci. 2015;112(47):E6456-65.

160. Pereira MCF, Brackley CA, Michieletto D, Annunziatella C, Bianco S, Chiariello AM, et al. Complementary chromosome folding by transcription factors and cohesin. bioRxiv. 2018

161. Nuebler J, Fudenberg G, Imakaev M, Abdennur N, Mirny LA. Chromatin organization by an interplay of loop extrusion and compartmental segregation. Proc Natl Acad Sci. 2018;115:E6697-706.

162. Le TB, Laub MT. Transcription rate and transcript length drive formation of chromosomal interaction domain boundaries. EMBO J. 2016;35(14):1582-95. .

163. Beagrie RA, Scialdone A, Schueler M, Kraemer DCA, Chotalia M, Xie SQ, et al. Complex multi-enhancer contacts captured by genome architecture mapping. Nature. 2017;543:519-24.

164. Olivares-Chauvet P, Mukamel Z, Lifshitz A, Schwartzman O, Elkayam NO, Lubling Y, et al. Capturing pairwise and multiway chromosomal conformations using chromosomal walks. Nature. 2016;540(7632):296-300.

165. Fullwood MJ, Liu MH, Pan YF, Liu J, Xu H, Mohamed Y Bin, et al. An oestrogen-receptor-a-bound human chromatin interactome. Nature. 2009;462(7269):58-64.

166. Davidson IF, Bauer B, Goetz D, Tang W, Wutz G, Peters J-M. DNA loop extrusion by human cohesin. Science. 2019: 366(6471):1338-45.

167. Golfier S, Quail T, Kimura H, Brugués J. Cohesin and condensin extrude DNA loops in a cell-cycle dependent manner. Elife. 2020;9:e53885. .

168. Brandão HB, Paul P, van den Berg AA, Rudner DZ, Wang X, Mirny LA. RNA polymerases as moving barriers to condensin loop extrusion. Proc Natl Acad Sci. 2019;116:20489-99.

169. Espinola SM, Götz M, Fiche J-B, Bellec M, Houbron C, Cardozo Gizzi AM, et al. Cis-regulatory chromatin loops arise before TADs and gene activation, and are independent of cell fate during development. bioRxiv [Internet]. 2020;2020.07. 07.191015. Available from: http://biorxiv.org/content/early/2020/07/07/2020.07.07.191015.abstract.

170. Schoenfelder S, Fraser P. Long-range enhancer-promoter contacts in gene expression control. Nat Rev Genet. 2019;1.

171. Nora EP, Goloborodko A, Valton AL, Gibcus JH, Uebersohn A, Abdennur N, et al. Targeted degradation of CTCF decouples local insulation of chromosome domains from genomic compartmentalization. Cell. 2017;169(5):930-44

172. Rao SSP, Huang SC, Glenn St Hilaire B, Engreitz JM, Perez EM, Kieffer-Kwon KR, et al. Cohesin loss eliminates all loop domains. Cell. 2017;171(2):305-20.

173. Guo Y, Xu Q, Canzio D, Shou J, Li J, Gorkin DU, et al. CRISPR inversion of CTCF sSites alters genome topology and enhancer/promoter function. Cell. 2015;162(4):900-10.

174. Lupiáñez DG, Kraft K, Heinrich V, Krawitz P, Brancati F, Klopocki E, et al. Disruptions of topological chromatin domains cause pathogenic rewiring of gene-enhancer interactions. Cell. 2015;161(5):1012-25.

175. Hnisz D, Weintrau AS, Day DS, Valton AL, Bak RO, Li CH, et al. Activation of proto-oncogenes by disruption of chromosome neighborhoods. Science. 2016;351(6280):1454-8.

176. Chen BC, Legant WR, Wang K, Shao L, Milkie DE, Davidson MW, et al. Lattice light-sheet microscopy: imaging molecules to embryos at high spatiotemporal resolution. Science. 2014;346(6208).

177. Huang X, Fan J, Li L, Liu H, Wu R, Wu Y, et al. Fast, long-term, super-resolution imaging with Hessian structured illumination microscopy. Nat Biotechnol. 2018;36(5):451.

178. Wu Y, Shroff H. Faster, sharper, and deeper: structured illumination microscopy for biological imaging. Nat Methods. 2018;15(12):1011-9.

\section{Publisher's Note}

Springer Nature remains neutral with regard to jurisdictional claims in published maps and institutional affiliations. 